Revista de Comunicación de la SEECI. (Noviembre 2013). Año XV (32), 12-30

ISSN: 1576-3420 DOI: http://dx.doi.org/10.15198/seeci.2013.32.12-30

\title{
INVESTIGACIÓN/RESEARCH
}

\section{WIKIPERIODISMO O PERIODISMO COLABORATIVO: ¿TIENE FUTURO?}

Elvira Calvo Gutiérrez ${ }^{1}$ : Universidad Complutense de Madrid. España. ecalvogu@ccinf.ucm.es

\section{RESUMEN}

El Wikiperiodismo, o la influencia de la cultura wiki hacia los medios de comunicación, es una nueva modalidad de periodismo basado en la inteligencia colectiva y el trabajo colaborativo. El objetivo de este artículo está enfocado a analizar algunos casos reales para extraer ventajas e inconvenientes y, consecuentemente, intentar dilucidar si el futuro del periodismo colaborativo es una moda pasajera o si conseguirá instaurarse en una sociedad cada vez mas abierta, mas tecnológica, mas participativa. Lo que ya parece demostrado es que los wikis son una de las mejores herramientas que la web 2.0 ofrece a la profesión periodística y al periodismo participativo, permitiendo crear, y abrir a toda la ciudadanía una especie de banco de datos, una web colaborativa, participativa e instantánea.

PALABRAS CLAVE: Wikiperiodismo - Periodismo colaborativo - Wikinoticias Cibermedios - Internet.

\footnotetext{
${ }^{1}$ Autor correspondiente:

Elvira Calvo Gutiérrez: Facultad de Ciencias de la Información de la Universidad Complutense de Madrid. España.

Correo: ecalvogu@ccinf.ucm.es
} 


\title{
WIKIJOURNALISM OR COLLABORATIVE JOURNALISM: HAS IT GOT A FUTURE?
}

\begin{abstract}
The influence of wiki culture on the mass media, called Wikiperiodismo, is a new type of journalism based on collective intelligence and collaborative work. The aim of this paper is analyzing some real cases to extract advantages and disadvantages and, consequently, trying to figure if the future of collaborative journalism is a fad or get instituted in a society increasingly open, more technology, more participatory. What already seems clear is that wikis are one of the best tools that Web 2.0 offers to journalism and participatory journalism, allowing to create and open to all citizens a kind of database, a web-collaborative, participatory and instantaneous.
\end{abstract}

KEYWORDS: Wikijournalism - Collaborative journalism - Wikinews - Cybermedia Internet.

\section{INTRODUCCIÓN}

El concepto de wiki se ha extendido gracias a los populares casos de Wikipedia y WikiLeaks. Estamos ante una de las herramientas mas populares de la web 2.0 junto a los blogs y los foros abiertos a la ciudadanía. Sus virtudes residen en la información y y participación instantánea y colaborativa, que lo convierten en fuentes informativas útiles en sectores tan diferentes como la educación, la industria editorial, los negocios, el marketing y, por supuesto, el periodismo. El profesor Klobas describía el wiki en un contexto de software social y de tendencia hacia un mundo cada vez mas interactivo (Klobas, 2006: 54).

Un wiki es una página web que permite a los usuarios crear y modificar sus contenidos de manera cooperativa permitiendo la escritura colaborativa, los usuarios trabajan sobre la misma pieza, por lo que las aportaciones se ven reflejadas en un texto en continua transformación, lo que supone la participación de la audiencia en el proceso informativo2.

La influencia de la cultura wiki ha llegado a la profesión periodística y ya se conoce como Wikiperiodismo. Profundicemos en el concepto y analicemos algunos ejemplos de esta herramienta 2.0 que puede ofrecer al periodismo, y a la ciudadanía, la creación de una especie de banco de datos, una web colaborativa, participativa e instantánea con utilidades diversas.

\footnotetext{
${ }^{2}$ http://blogs.lavanguardia.com/elcuartobit/ [Consultado el 13.9.2013]
} 


\section{METODOLOGÍA}

Para la realización de este trabajo ha sido imprescindible la consulta a referencias bibliográficas que han servido para la profundización conceptual, conocer los antecedentes históricos y conocer las aportaciones de los gurús tecnológicos, la mayoría de EEUU, en relación a los wikis como poderosa herramienta social media.

Anteriormente, y para centrar el concepto a desarrollar, se ha realizado un exhaustivo resumen de los casos mas conocidos: Wikipedia y Wikileaks de los que se han extraídos aspectos menos novedosos. Recordando la esencia de ambos casos, a los lectores les resultará mas fácil entender la extensión del concepto al campo del periodismo.

Por último, se ha realizado un estudio de los casos de wikiperiodismo mas conocido, a nivel nacional e internacional, para poder concluir con un análisis que intenta dilucidar el futuro de esta herramienta 2.0 en el marco de la profesión periodística y que conlleva, indefectiblemente, la participación de la audiencia en el proceso informativo.

\section{ANÁLISIS Y DISCUSIÓN}

\subsection{Enciclopedias colaborativas.}

Las wikipedias son elaboraciones de enciclopedias generales y especializadas por los usuarios sobre diversos campos temáticos o geográfícos también con sus variantes de audio y vídeo, además de la escritura (Cebrián, 2008). Recogen contenidos producidos por unos usuarios y que otros pueden ampliar o modificar. Es una apertura al conocimiento universal aportado por los ciudadanos. Cada vez son más las variantes: wikipedias escritas, sonoras o habladas, fotográficas, audiovisuales; wikinarios o diccionarios; wikiguías de ciudades; wikipedias de noticias o sobre determinados conocimientos.

Sin embargo, señala Cebrián, frente a sus grandes aportaciones a un conocimiento concreto, las wikipedias presentan riesgos importantes al dar entrada a cualquier artículo sobre cualquier realidad elaborado por cualquier persona que, incluso, carece del conocimiento suficiente. En lugar de ser una aportación rigurosa al conocimiento se convierte en algo devaluado. Mayor riesgo se produce cuando las empresas o instituciones intervienen para modificar algunas aportaciones. No siempre es para mayor precisión y enriquecimiento, sino para ocultar otras realidades, manipularlas o dar la versión que a ellas les interesa aunque no sea veraz

Cuando se habla de wikis, se piensa inmediatamente en Wikipedia, la enciclopedia colaborativa que se codea, en Internet, con la venerable Britanica y que fue creada por Ward Cunnigham en 1994 . Si las enciclopedias son un compendio del conocimiento acumulado por la humanidad, Wikipedia refleja también qué conocimiento es el más compartido, puesto que tanto el contenido como la propuesta de entradas las hacen los propios usuarios. 
En realidad, Cunningham inventó un método de colaboración rápida en la red que, además de permitir el acceso, invita a los usuarios a editar cualquier página o crear nuevas a través de un software básico. Desde su expansión, los wikis constituyen un sistema común de elaborar documentos colectivos y aunque el más famoso y popular de los sitios que han generado es la Wikipedia, se emplean en realidad para muchos otros propósitos. Uno de ellos es el periodístico.

Wikipedia no deja de ser un ejemplo más de la aplicación de nuevas herramientas infotecnológicas, los wikis, para una aplicación muy específica y entendida en términos tradicionales, es decir construir una enciclopedia, eso sí, en colaboración, con la participación, en principio, de cualquier usuario anónimo con voluntad de contribuir al proyecto. De este hecho debemos extraer una o dos ideas claras: los wikis no son sólo la Wikipedia; y ésta no se aleja -en su concepción centralizada y controlada por una creciente jerarquía de bibliotecariosde los clásicos reservorios de información que ya conocíamos (Fumero 2007: 56).

Wikimedia ${ }^{3}$ es un osado experimento iniciado en 2001 con el propósito de construir un sitio web para presentar contenido actualizado, relevante, noticioso y entretenido sin prejuicios. Wikimedia resulta ser un movimiento global cuya misión es traer contenido educativo gratuito al mundo. Se trata de una organización sin ánimo de lucro instituida bajo las leyes de Florida (Estados Unidos). Su existencia fue oficialmente anunciada por el director general de Bomis y co-fundador de Wikipedia, Jimmy Wales el 20 de junio de 2003.

A través de varios proyectos, capítulos y la estructura de apoyo de la Fundación no lucrativa Wikimedia, se esfuerza por hacer un mundo mejor, en el que cada ser humano libremente pueda compartir todo el conocimiento. Su creación ha permitido que cerca del $10 \%$ del mundo (aquellos con acceso a Internet) creasen una enciclopedia en todos los idiomas, disponible de manera libre para todos en el planeta que tuvieran acceso a la red, para siempre. En los siguientes meses y años, no era solamente la tecnología la que hacía este sueño una realidad, sino también una comunidad de voluntarios increíblemente dedicada que escribía artículos y formulaba las políticas y guías para el proyecto. Lo hicieron mediante un proceso abierto y revolucionario, en la convicción de la posibilidad de un consenso, con el deseo del mejoramiento de la condición humana y enamorados del espíritu humano.

Como organización matriz, Wikimedia hospeda numerosas wikis temáticas, con diferentes ediciones idiomáticas, todas enlazadas en Wikpedia:

1. Wikipedia: la enciclopedia libre.

2. Wiktionary: Diccionario con mas de diez idiomas diferentes, incluidos el árabe y el chino.

3. Wikiquote: Colección de citas y frases famosas en una decena de idiomas europeos.

4. Wikibooks: Colección de libros de contenido libre de países europeos

5. Wikisource: La biblioteca libre para creación de libros

\footnotetext{
${ }^{3}$ http://www.wikimedia.org/ [Consultado el 16.9.2013]
} 
6. Wikinews: Fuente de noticias de contenido libres en varios idiomas.

7. Wikivesity: Comunidad de aprendizaje libre con contenidos académicos en varios idiomas.

8. Wikispecies: Directorio libre de especies naturales de flora y fauna.

9. Mediawiki: Proyectos de software.

10. Etc.

Los wikis se han aplicado en proyectos periodísticos, como Wikinews ${ }^{4}$, o Wikinoticias en su versión española, y sus hermanos multilingües con una trayectoria, de momento, modesta. La wiki periodística por excelencia de Wikimedia es una fuente de noticias de contenido libre que permite la publicación de artículos a cualquier ciudadano. Busca que los individuos contribuyan con informes acerca de eventos, grandes y pequeños, desde la experiencia personal o de la realidad observada. Wikinoticias está basado en la idea de crear algo nuevo más que destruir algo viejo, en la creencia de poder construir un recurso grande y único que enriquecerá el paisaje mediático. Su meta es ser, algún día, un recurso útil por sí mismo y ofrecerse como alternativa a las grandes agencias de noticias como Associated Press, EFE o Reuters; es decir, también permitirá que medios independientes se equipen para conseguir una fuente de noticias gratuita de alta calidad.

Gracias al copyleft, cualquiera puede crear su propia fuente de noticias libres disponibles de manera permanente y no requieren registro para leerlos. Wikinoticias adopta los principios que han hecho de Wikipedia y de los otros sitios de la Fundación Wikimedia lo que son hoy: neutralidad, contenido libre y un proceso de toma de decisiones abierto. Busca promover la idea del periodista ciudadano, pues creen que cualquiera puede realizar una contribución útil para crear la gran imagen de lo que sucede en el mundo, una fuente de noticias libre, por la gente y para la gente.

Aunque mas adelante se desarrollo el nuevo rol del periodista ante este nuevo modelo de periodismo, se hace indispensable preguntarse aquí dónde queda el papel del periodista profesional. "El paso de la función de gatekeeper profesional al periodista ciudadano o al ciudadano usuario de las redes, define un modelo de producción de contenidos peligrosos para el cibernauta. Los modelos wikis necesitan crear y contar con un control profesional si pretender ser considerados como espacios de producción de noticias y si pretenden, como bien lo señalan sus mismos creadores, ser una alternativa a las agencias de noticias existentes" (Tornero y Tejedor en Cebrián, 2010: 234).

\subsection{El caso WikiLeaks.}

A pesar de su nombre, WikiLeaks no es un sitio wiki habitual, ya que realmente los lectores que no tienen los permisos adecuados no pueden cambiar su contenido. Sin embargo, su alusión es inevitable. WikiLeaks (del inglés leak, «fuga», «goteo», «filtración [de información]») es una organización mediática internacional sin ánimo de lucro que publica, a través de su sitio web, informes anónimos y documentos

\footnotetext{
${ }^{4}$ http://es.wikinews.org/wiki/Portada [Consultado el 3.10.2013]
} 
filtrados con contenido sensible en materia de interés público, preservando el anonimato de sus fuentes. El lanzamiento del sitio se realizó en diciembre de 2006, su actividad comenzó en julio de 2007 y desde entonces su base de datos ha crecido constantemente hasta acumular 1,2 millones de documentos. Su creador fue Julian Assange. WikiLeaks usa una versión modificada del software de MediaWiki3 y su servidor principal está alojado en el ISP sueco PRQ. Para proteger el anonimato de sus informantes, WikiLeaks utiliza OpenSSL, Freenet, Tor y PGP. Está gestionado por The Sunshine Press ${ }^{5}$.

La organización se ofrece a recibir filtraciones que desvelen comportamientos no éticos por parte de gobiernos, con énfasis en los países que considera tienen regímenes totalitarios, pero también de religiones y compañías de todo el mundo. Por el momento, las actividades más destacadas de WikiLeaks se han centrado en la actividad exterior de los Estados Unidos, especialmente en relación con las guerras de Irak y de Afganistán.

WikiLeaks se describe a sí misma como una organización fundada internacionalmente por disidentes chinos, así como por periodistas, matemáticos, y tecnólogos de empresas start-up de los Estados Unidos, Taiwán, Europa, Australia y Sudáfrica. Los creadores de WikiLeaks no han sido formalmente identificados, salvo uno de sus asesores, redactor jefe y director, el australiano Julian Assange. Ante su detención el 7 de diciembre de 2010, tomó las riendas de la organización Kristinn Hrafnsson, después de la renuncia de Daniel Domscheit-Berg, quien anunció en enero de 2011 la creación de su propio portal de filtraciones, OpenLeaks ${ }^{6}$, aunque a mediados de 2012 nada se sabe de sus proyectos.

La alianza entre Wikileaks y el conocido colectivo de hackers Anonymous ha levantado mucha suspicacia y críticas. El crecimiento de la popularidad de Wikileaks parece el argumento de una novela de ciencia ficción: una organización global, conformada por hackers y anarquistas, apoyada por abogados especialistas en la libertad de expresión, como la islandesa MP Birgitta Jonsdottir, y activistas como Jacob Appelbaum, saca a la luz un inmenso contingente de vídeos y documentos clasificados que obtiene de un intrépido ex analista de inteligencia militar, Bradley Manning ${ }^{7}$ (actualmente en la cárcel por espionaje y, además, nominado al Nobel de la $\mathrm{Paz}^{8}$ ).

La irrupción de Wikileaks no sólo ha tenido consecuencias para la diplomacia. También el periodismo se ha visto en el puto de mira. Como afirma el profesor de Periodismo y comunicación Política en la George Washington University, Silvio Waisbord ${ }^{9}$, ya no existen más secretos; o es muy difícil mantenerlos como tal: alguien puede acceder a documentos depositados en un servidor y hacer copias que adquieren vida y velocidad propia. La posibilidad que se revele información de la red de seguridad del gobierno

\footnotetext{
${ }^{5}$ http://es.wikipedia.org/wiki/Wiki [Consultado el 24.10.13]

6 http://openleaks.org/ [Consultado el 24.10.13]

7 http://www.bradleymanning.org/ [Consultado el 24.10.13]

8 http://www.publico.es/internacional/424233/el-soldado-bradley-manning-nominado-al-nobel-de-la-paz [Consultado el 24.10.13]

${ }^{9}$ http://www.lanacion.com.ar/1333057-la-irrupcion-del-wikiperiodismo [Consultado el 22.10.13]
} 
de Estados Unidos (Siprnet), a la que tienen acceso casi tres millones de funcionarios, es permanente. Pero más allá del impacto diplomático, Waisbord se pregunta si WikiLeaks es periodismo, ese periodismo de investigación que la renovada democracia está trayendo a la palestra. WikiLeaks podría representar un nuevo tipo de periodismo en un mundo informativo en profunda transición ya que podría ser uno de los pocos ejemplos de periodismo realmente globalizado: su público es una audiencia global, su mira está puesta en cuestiones que trascienden la política nacional, y sus fuentes de información ( $y$, según se especula, de financiación) son globales. El hecho de que WikiLeaks escoja determinados periódicos para la distribución de información sugiere que los diarios siguen siendo fundamentales en visibilidad y credibilidad. WikiLeaks por sí solo no hubiera ocasionado semejante conmoción.

No es la pura lógica periodística lo que impulsó las decisiones de WikiLeaks; coexisten lo periodísticamente interesante con los detalles superfluos, que rara vez son noticia. Es información en crudo, ofrecida sin el filtro típico de la redacción. El sensacionalismo de las revelaciones que involucran a los poderosos del mundo entra en la misma bolsa con observaciones pedestres e irrelevantes. El periodismo convencional tamiza mucho más que WikiLeaks, que sacude descargando información en bruto. Quizá la prueba más contundente del wikiperiodismo es que sus acciones son interpretadas como si efectivamente fuera periodismo. No es cuestión de si WikiLeaks hace periodismo, sino que se cree que, efectivamente, es periodismo. Quienes apoyan a Assange sostienen que la virtud de WikiLeaks es exactamente lo que la buena prensa debe hacer en democracia: ofrecer información para ayudar a los ciudadanos a entender el funcionamiento del gobierno y mantener un escepticismo prudente frente al poder. En opinión de Weisbord, WikiLeaks y los medios que diseminaron las filtraciones cumplen funciones vitales a la prensa en su servicio a la democracia liberal. Más allá de la excesiva arrogancia de Assange y la falta de transparencia de su operación, su empecinamiento en desnudar al poder de la primera potencia mundial es digna del mejor periodismo.

\subsection{La irrupción del Wikiperiodismo.}

Lo mas importante de la web 2.0 es la participación ciudadana que fomenta (Cebrián, 2008). Los usuarios ya no son meros receptores pasivos, ni siquiera meros receptores activos e interactivos. El gran cambio procede de la capacidad que se les da para la creación y producción de informaciones y mensajes. Hablamos ya de periodismo ciudadano en el que las personas se convierten en fuentes informativas 0 buscadores de informaciones, en otras fuentes para compartirlas con los demás. En la web 2.0 la sociedad civil ya no se dedica sólo a la recepción o búsqueda, sino también a la producción y difusión de información.

El éxito de los wikis en el nuevo sistema de información ha dinamizado la cooperación de la actividad periodística. Muchos se preguntan por el futuro de los medios de comunicación: ¿existirán medios en el sentido clásico de la palabra? El mundo sobrevivirá si la esencia del periodismo -contar lo que pasa a los demás- se mantiene. Google es un buen ejemplo para esta interrogante porque se ha convertido en un 
medio de comunicación: la primera fuente informativa para los estadounidenses ya es Google News ${ }^{10}$.

Pero vayamos al fondo de la cuestión ¿qué virtudes ofrecen los wikis al periodismo? $\mathrm{Si}$ nos fijamos en Wikipedia, la gratuidad y la participación, sin duda. Pero no las únicas. La periodista catalana enumera otras claves del éxito de la enciclopedia digital: las correcciones con debate (es una enciclopedia en constante mutación y el proceso de debate asociado a cada entrada está a la vista de todos lo que permite que el pulso por la neutralidad y las definiciones fundamentadas dan lugar a argumentos y refutaciones enriquecedores) y la actualidad inmediata (los ciudadanos pueden informar de cualquier hecho que consideren noticiable, lo que implica contar también realidades que no aparecen habitualmente en los medios).

Así pues, el debate, el registro de cambios, la facilidad de uso y de modificaciones convierten a los wikis en plataformas de trabajo dinámicas y cómodas que se están extendiendo a muchos ámbitos, desde los empresariales hasta los educativos, pasando por los periodísticos como se muestra en el próximo epígrafe.

Aludíamos al inicio de este capítulo a la paradoja entre la popularidad del concepto wiki y el grado de utilización de la herramienta por parte de los cibernautas. Una posible causa podría encontrarse en la dificultad, mas bien el desconocimiento, del proceso (Woods y Thoeny, 2007: 10-11). Como señala José Antonio del Moral, cada herramienta de wiki tiene una sintaxis propia, lo que complica cada edición, si bien es cierto que en los últimos años se está trabajando en generar un estándar aplicable. Sobre cuándo y cómo crear un wiki sabe mucho José Antonio del Moral, autor del capítulo número 3 del libro "Web 2.0 Manual [no oficial] de uso" (VVAA, 2007: 45-60).

Hay numerosos casos que muestran la extraordinaria utilidad de los wikis en las investigaciones periodísticas y su aportación al desarrollo del periodismo ciudadano. Sin embargo, después de algunos años hablando del tema y de corroborar que, en el mundo wiki, la velocidad y la interacción instantánea es la clave, como afirma Anaís Madrid $^{11}$, muchas voces se han alzado en contra. El argumento es que lo que se gana en participación se pierde en garantía de la calidad del producto, lo cual no parece preocupar al usuario para quien, de momento; lo importante es sentirse capaz de influir en la elaboración de una enciclopedia, una biblioteca universal o una noticia. El manejo de la información es evidente, por eso muchos expertos temen que el Wikiperiodismo puede deslizarse fácilmente hacia el wikipopulismo. El problema al que nos enfrentamos los profesionales de la información es conocer cómo podemos ser mediadores y ayudar a los ciudadanos a ejercer sus opciones.

\subsubsection{Wikiperiodismo, Periodismo ciudadano y wikipopulismo.}

La mutación de Wikiperiodismo en wikipopulismo es un problema que preocupa a varios autores como se ha recogido ya. Uno más es la del directivo del grupo Prisa,

\footnotetext{
${ }^{10}$ http://news.google.com.mx/?edchanged=1\&ned=es_us\&authuser=0 [Consultado el 22.09.13]

${ }^{11}$ http://elimperdible.ec/web/observatorio/wiki-wiki-\%C2\%BFwikiperiodismo.html [Consultado el 22.09.13]
} 
Juan Luis Cebrián, cuyo discurso de apertura del curso 2011 de la Escuela de Periodismo de El Paín pronunciaba en febrero de 2012. "Podríamos decir que el Wikiperiodismo es al periodismo lo que la Wikipedia a las enciclopedias clásicas". Aunque aparentemente se trata de productos parecidos y responden a una demanda muy similar, las diferencias que albergan entre ellos son profundas: en el mundo wiki la interacción instantánea es la clave, el conocimiento es colectivo y, en principio, no hay un liderazgo visible o demostrable al que atribuir la responsabilidad del rigor intelectual. "Lo que se gana en participación se pierde en garantía de la calidad del producto" afirma Cebrián.

El profesor Ruiz Soroa, recuerda Cebrián, afirma que "sólo el pueblo no puede formar una voluntad, no puede tomar una decisión, porque le falta el indispensable polo de alteridad que le falta para ello", lo que se significa que, sin los elementos de representación política, el poder del pueblo quedaría reducido a la opinión pública o, en definitiva, a la aclamación. La democracia es un sistema basado en la opinión pública, pero necesita sobre todo de la opinión publicada, de la discusión y la contradicción, en el ejercicio del poder representativo. "La facilidad con que el Wikiperiodismo puede deslizarse hacia el wikipopulismo en el manejo de la información es demasiado evidente. Pero el problema reside de nuevo averiguar cómo podemos los mediadores, seamos periodistas o políticos, ayudar a los ciudadanos a ejercer sus opciones si ese principio de alteridad desaparece". La consecuencia práctica es que muchos ciudadanos otorgan una credibilidad inaudita a las mentiras, rumores, calumnias y disparates de los confidenciales y blogueros, que desdicen del rigor periodístico de los medios tradicionales. Cebrián asemeja esta preferencia con la de los estudiantes de todo el mundo por la Wikipedia en lugar de la edición digital de la Enciclopedia Británica.

Cebrián reclama liderazgo por parte de la profesión. "El populismo reinante, nacido como reacción al absolutismo burgués, no puede perdurar por mucho tiempo. Los ciudadanos aman la libertad de elegir, pero les cansa hacerlo a cada minuto .... pervivan o no los periódicos, lo harán los periodistas, se llamen como se llamen, y seguirán siendo necesarios. La ciudadanía seguirá necesitando, quizá más que nunca, gente con las tripas, el corazón y la voluntad de servir a sus vecinos mediante ele ejercicio de contarles la verdad y desvelarles los secretos que el poder pretende ocultar. Esas gentes han de tener la inteligencia y la capacidad de análisis, el sentido común y el bagaje de formación necesarios para ejercer esa tarea de forma racional, para apoderarse del software y ponerlo a disposición de la comunidad". En su discurso, Cebrián defiende el periodismo de calidad por encima de la opinión pública que genera el "wikipopulismo" y aboga por un periodismo profesional que sirva de guía a los consumidores de información, ejerciendo el liderazgo de una colectividad. Sin embargo, este liderazgo no se consigue de la noche a la mañana y, entre otros, muchos blogueros llevan tiempo trabajándolo (o simplemente consiguiéndolo). 
Como señala el profesor Pablo Díaz Luque ${ }^{12}$, "el wikipopulismo, como el periodismo sensacionalista y la telebasura, existirá siempre. La contraposición perdurable y comprobable de un periodismo serio, no sujeto a vaivenes políticos, suena a imprescindible. Igualmente, la contraposición de la opinión pública generada por blogueros serios, contrastados, imparciales, documentados, bien informados, buenos investigadores y redactores, también lo es. Además, resulta más fácil confiar en un bloguero con criterio en el tiempo y transparencia demostrable, que en una organización periodística y sus entrañas", argumentos estos que obligan a hacer un esfuerzo social generalizado por dotar de wikinformación de calidad a la sociedad frente al wikipopulismo.

\subsubsection{Blogs y wikis: ¿̇parecidos razonables?}

Denominamos Wikiperiodismo al uso periodístico de wikis y blogs, dos herramientas que ofrece la web 2.0 realmente muy similares en cuanto a que se basan en la participación activa de los usuarios. Por ello, resulta fundamental en este capítulo aludir a las diferencias entre ambos instrumentos. Y para ello, vamos a utilizar un ejemplo, cuyo protagonista utiliza un blog para contar con la participación y colaboración ciudadana.

Hugo Alconada, periodista y abogado argentino, es autor de dos libros de investigación, "Los secretos de la valija" (2009) y "Las coimas del gigante alemán" (2011) sobre la corrupción en Argentina y Venezuela. Utiliza el blog Valijeros.blogspot.com.es para aportar datos y para que sus seguidores le aporten informaciones que el contrasta lógicamente. Es lo que él llama wikiperiodismo 2.0 y que explica en tres fases, todo un proceso en el que, gracias a las informaciones de los usuarios, puede construir historias: En primer lugar, el periodista tiene un determinado material con el que escribe y publica un libro que se promociona en un diario: periodismo tradicional; después, ese material comienza a difundirse por las webs tradicionales de noticias: periodismo digital 1.0; por último, las noticias comienzan a subirse a páginas de Internet, blogs y foros = Wikiperiodismo 2.0, es decir, una interacción entre periodistas, blogueros y usuarios de foros que aportan información para un segundo libro.

El parecido entre blog y wiki es razonable. Ambos conceptos tienen conceptos comunes a las web 2.0: ambas son webs de lecto escritura, utilizan servidores gratuitos, se publican en red y no necesitan un software específico. Los blogs son un medio de publicación personal pero publicar no es informar. Cuando un blgo pretende ofrecer contenido informativo, lo hará en la medida en que su autor publique una información elaborada y verificada (Baviera, en Flores y Esteve, 2009: 333). El desarrollo de los blogs ha sido espectacular en los últimos años, sin embargo, una de las premisas es su continuidad y muchos mueren antes de llegar al año de vida. Es una diferencia importante en relación con los wikis que se utilizan para investigación periodística: nacen con un objetivo, recopilar información de los usuarios, y una vez

12 http://mundowiki.com/2011/02/25/wikiperiodismo-\%C2\%BFun-problema-de-liderazgo/ [Consultado el 12.10.13] 
alcanzado su objetivo, pueden morir o permanecer como testigos de una investigación, dependerá de los fundadores.

\section{4. ¿Tiene futuro el periodismo colaborativo?}

En el mismo discurso de Cebrián al que acabamos de hacer referencia, el académico hacía una alusión a la Wikipedia. "Lo que Cunningham inventó -dice Cebrián- lo describe él mismo: es un método de colaboración rápida en la red, que permite e invita a los usuarios a editar cualquier página o crear páginas nuevas mediante un software sencillo y estándar. Los wikis constituyen un sistema común de elaborar documentos colectivos y aunque el más famoso y popular de los sitios que han generado es la Wikipedia, se emplean en realidad para muchos otros propósitos. Póngase atención en el hecho de que la velocidad o instantaneidad son características prioritarias de este proceso, como en realidad lo son de todo el universo de la sociedad digital". Coincide el que fuera primer director de El País con lo expuesto aquí en relación con las claves del éxito de los wikis: interacción y cooperación. "A partir de ese enunciado -dice Cebrián- podemos deducir fácilmente lo sustancial del problema: nos preguntamos por el futuro de los medios de comunicación, el periodismo incluido, al tiempo que entronizamos una sociedad desintermediada". Cebrián no se pregunta tanto por el papel de los medios o su nuevo modelo de negocio en la sociedad digital sino si van a existir medios en el sentido clásico de la palabra. En definitiva, si la esencia del periodismo, que consiste en contar lo que pasa a los demás, va a sobrevivir en un mundo en el que cada cual es capaz de comunicar sus experiencias por sí mismo, a todo el mundo y sin necesidad de mediación alguna.

El Wikiperiodismo es una forma de periodismo -a desarrollar en la red-, instantánea, rápida y cooperativa, en la que los comunicadores de las noticias son, por lo general, los protagonistas de las mismas por lo que el efecto de intermediación desaparece. Los intermediarios -politicos, económicos, etc.- han tenido siempre mala fama, no general valor añadido, les mueve el dinero, comisiones escandalosas e innecesarias. Frente a ellos, la venta directa gana adeptos, de ahí la guerra con las marcas a favor de los genéricos en la industria farmacéutica. Pero el resultado ¿es un descenso de la calidad del producto y de las garantías sobre las prestaciones del mismo? ¿o no?

En política, para Cebrián, la desintermediación parece confundirse con la democracia directa que, desgraciadamente, en muchos casos se ha deslizado siempre peligrosamente hacia el populismo y ha sido un instrumento frecuentemente utilizado por dictadores y regímenes totalitarios. La distinción que reclamaba Felipe González entre la opinión pública y la publicada -aquí Cebrián reconoce que partidos políticos y medios de comunicación son facetas de un único mecanismo de funcionamiento del Estado y de articulación del poder, que ha pervivido en las democracias por más de doscientos años- ha sido sustituida por Wikipolítica y Wikimedia cuando el sistma ha entrado en crisis a partir de la revolución digital.

El verdadero debate que se abre sobre el futuro de los periódicos a partir de su irrupción en la red es, según Cebrián, cómo la eliminación de los elementos tiempo y espacio en el universo digital va a influir en la construcción de la convivencia y en el 
método de conocimiento y comunicación entre los ciudadanos. Todo el conocimiento existente se encuentra ya en la red y que los motores de búsqueda son una herramienta poderosísima para cualquier reportero, que hace una década no existía. Independientemente de las facilidades técnicas y del cambio en las condiciones económicas, de rentabilidad y financiación del proceso, este se caracteriza porque se centra en la personalización del usuario, la habilidad de éste para relacionarse con el emisor, y la universalización de las noticias. También por el hecho de que nos dirigimos a un mercado global e instantáneo, que hace perecer prácticamente la mayoría de los ritos y hábitos de nuestra profesión.

En su propuesta de transición hacia un nuevo modelo de redacción en los medios de comunicación, Bradshaw (2007) propone varios pasos. Uno de ellos es la interactividad y dice: "Aunque exige inversiones y preparación, tiene la capacidad de atraer e informar a los usuarios de un modo que otros medios no pueden, así como proporcionar un recurso de 'larga cola' que genere repetidas visitas en un largo plazo temporal: puede que lleve días producir un flash interactivo, pero puede suponer una irresistible combinación de hipertexto, vídeo, audio, animación y bases de datos (también puede ser actualizada dinámicamente); un foro puede proporcionar un lugar en el que la gente se reúna y cuelgue experiencias e información; un wiki puede hacer todo eso pero con mayor eficacia".

Durante los últimos años las redes sociales han protagonizado una inmersión definitiva en las rutinas de los medios y en las pautas de consumo informativo de la audiencia. La recomendación social se ha convertido en un paradigma periodístico que los medios deben aprender a manejar (Noguera, 2012: 21). Los desafíos que el nuevo escenario mediático presenta a los periodistas en general pasa por la gestión de la identidad online y las redes de periodistas como nuevo modelo de medio. Las formas, la práctica y la epistemología del periodismo digital ya forman parte de nuestra cultura (Allan, 2006: 82). Evaluar sus implicaciones nos ayudará a asimilar y a vislumbrar el futuro mas inmediato del periodismo. El argentino Luis Albornoz, tras un análisis comparativo de las ediciones web de los seis principales periódicos en lengua castellana: Mundo.es (España), Clarín.com (Argentina); Reforma.com (México), ElPais.es (España), Abc.es (España) y LaNacion.com (Argentina), concluye que el periodismo digital es un sector inestable, donde nada es definitivo, frente a los aspectos económicos y organizativos de las empresas periodísticas en Internet que sí son más estables (Albornoz, 2007: 76).

La capacidad de "pensar en línea" es la habilidad más importante para un periodista del siglo XXI. Los futuros profesionales tienen que adquirir ésa y otras habilidades que les ofrece Internet (Briggs, 2007: 122).

\subsubsection{Algunos casos de Wikiperiodismo.}

Llegados a este punto, queda claro la utilidad de los wikis para usos periodísticos. El potencial se encuentra en la colaboración (compartir, corregir, añadir) que permite un periodismo mas completo. Veamos ahora algunos casos reales de colaboración entre medios tradicionales y audiencia, y de wikis generales que también podrían servir al 
periodismo, así como la proyección, o éxito, que han obtenido. Comprobarán que sigue siendo fundamental el papel del periodista, verificador de esas nuevas informaciones.

\section{a) Los Angeles Times y su Wikitorial}

Los Angeles Times fue uno de los primeros diarios que se aventuró con los wikis y lo hizo, nada menos, que para su sección de Opinión. En 2005, sus directivos consideraron que abrir el proceso de elaboración de sus editoriales daría protagonismo a sus lectores, lo cual, por otro lado, se convertiría en una irresistible arma de fidelización. Así que el 17 de junio se aventuró a poner en marcha Wikitorial. El experimento duró tres días: el wiki se colapsó de insultos e improperios y descalificaciones de los usuarios, lo que desbordó la capacidad de moderación del medio. La experiencia fue un desastre y el error estribó en querer documentar o aportar datos a la propia opinión del medio. Un editorial refleja la filosofía y la personalidad del medio, tiene su estilo propio y personal, lo que entra en contradicción con la variedad de estilos de muchos lectores.

\section{b) Un artículo para Esquire que pasó antes por Wikipedia}

Por las mismas fechas, unos meses después, en septiembre de 2005, el periodista de Squire, Arnod Stephen Jacobs, mas conocido como A. J. Jacobs experimenta, con el beneplácito de Jimmy Walles, el poder de Wikipedia. Colgó un artículo de 709 palabras y 14 párrafos, en el que incluyó algunas directrices estilísticas y, deliberadamente, varios errores. A las 24 horas, los usuarios habían realizado 224 revisiones, y en las 24 horas siguientes, otras 149. El artículo final, que fue protegido el 23 de septiembre para publicado en Squire en el mes de diciembre, reflejaba el esfuerzo de los usuarios. En dos días, 373 revisiones. Jacobs dio el visto bueno a la versión resultante, 771 palabras y 15 párrafos y consideró muy positiva a experiencia13 sobre cómo una revista puede utilizar a sus lectores para hacer un periodismo mas completo, que fue publicada en Squire

\section{c) Wired News}

Otro experimento curioso fue el de Wired News ${ }^{14}$. El portal publicó el 9 de julio de 2006 un artículo titulado "Veni, Vidi, Wiki"15, escrito originalmente por Ryan Singel y editado colaborativamente en un wiki a disposición de todos los usuarios que actuaron añadiendo enlaces, cuestionando afirmaciones, sugiriendo nuevas fuentes de información e, incluso, entrevistando a un académico e incluyendo las citas. El tamaño del artículo se duplicó hasta que alguien tuvo que recortarlo para hacerlo atractivo. Singel publicó sus impresiones de la experiencia en el artículo The Wiki That Edited $\mathrm{Me}^{16}$, mostrando el modo en el que se estaba utilizando la herramienta y confirmó que el artículo final había ganado en precisión.

\footnotetext{
${ }^{13}$ http://news.cnet.com/Esquire-wikis-article-on-Wikipedia/2100-1038_3-5885171.html [Consultado el 6.10.13]

${ }^{14}$ http://www.wired.com/ [Consultado el 6.10.13]

15 http://www.wired.com/science/discoveries/news/2006/09/71733 [Consultado el 6.10.13]

16 http://www.wired.com/science/discoveries/news/2006/09/71737 [Consultado el 8.10.13]
} 
Sin embargo, la figura del mediador, en este caso la persona que metió el tijeretazo, fue imprescindible como equilibrador de la demanda y los intereses empresariales que demanda mas precisión y menos relato. Singel concluía que en el wiki confluyen los dos tipos de edición que hay que realizar en un escrito periodístico: la corrección estilística y la corrección informativa ("fact-checking"), es decir, comprobar que el artículo cuenta con las fuentes adecuadas y los hechos están referenciados correctamente. En el proceso de escritura en un wiki ambas se mezclan, edición estilística y edición informativa: los colaboradores añaden información que creen fundamental y también reescriben partes del artículo. Indudablemente, el conocimiento de los usuarios puede mejorar la documentación de la historia, como lo comprobó Singel. En una tesis similar se apoyan Leuf Bo y Ward Cunningham en su obra "The Wiki Way: collaboration and sharing on the Internet" (2001: 385-386)

\section{d) La Cantuta, usando la wiki para investigaciones periodísticas}

La Cantuta es el título de un libro y un documental (estrenados en marzo de 2011) sobre un episodio específico del terrorismo en Perú para el que sus autores utilizaron un blog y herramientas 2.0 para profundizar en el trabajo de búsqueda de información de Edmundo Cruz, un veterano periodista de investigación que lleva casi 20 años investigándolo. Una de esas herramientas fue, precisamente, un wiki que puso en marcha el editor del blog, Jonathan Castro. Fue, sobre todo, una idea solidaria con los personajes que tuvieron que ver con el caso, para que todos pudieran contar sus testimonios.

El wiki fue sólo una parte del proyecto web -además del documental, el libro, la web y el blog-. Fue una investigación muy larga que contó con muchos actores. Era fácil que el público (lector, usuario, telespectador) se perdiera en el maremagnum de personajes, de forma que podían recurrir al wiki para aclarar dudas sobre quién era quién. El público objetivo fueron jóvenes familiarizados con las redes sociales que no tenían más que ideas generales sobre el caso. Los usuarios fueron aportando datos nuevos, o correcciones, principalmente, con archivos de imágenes y noticias impresas escaneadas. La idea en general del blog fue preparar al público para la publicación del libro y del documental. El propósito de los autores fue despertar el interés, no por lo conocido -los familiares, las marchas-, sino por el lado de la investigación periodística: la búsqueda de la verdad sobre los hechos. Además, buscaban mostrar lo que efectivamente hizo el gobierno de Alberto Fujimori para tratar de dejar en la impunidad el caso: amenazas a congresistas, juicios ligeros en el fuero militar, uso de la fuerza para impedir investigaciones en el Congreso y la fiscalía, etc.

La idea fue ir compartiendo poco a poco todos los documentos: portadas de los diarios (para tener un panorama mediático), hechos que sucedían en la época (contexto), pedazos de las entrevistas que fueron filmadas para el documental, los 24 artículos de la investigación original en la revista Sí, reportajes televisivos y otros materiales que ayudaron al esclarecimiento de las responsabilidades. 


\section{e) 15Mpedia, una wikipedia para documentar el 15-M}

En España, un caso reciente de wiki es la 15 Mpedia $^{17}$, una enciclopedia libre y colaborativa que propone aglutinar todos los materiales y documentos sobre el Movimiento 15-M en una misma página y con un formato y estilo similares a Wikipedia.

"Si podemos recoger todo el contenido sobre el 15-M en un solo sitio y convertirlo en un lugar de referencia en cuanto a documentación, será positivo", explica Patricia Horrillo, de 35 años y una de los tres impulsores del proyecto, junto con el autor de documentales Stéphane Grueso y el programador Pablo Soto ${ }^{18}$. La idea comenzó a barruntarse cuando se dieron cuenta de que tratar de recoger todas las protestas, manifestaciones o acampadas realizadas en numerosas ciudades en un documental 0 un libro era algo inabarcable. Decidieron entonces poner en marcha la wiki.15M.cc, una iniciativa de tipo colaborativo, sin ánimo de lucro y con licencia copyleft que en apenas un mes, junio de 2012, cuenta con 467 artículos.

En la 15MPedia cualquiera puede subir un artículo para documentar alguna de las actividades surgidas al calor de las protestas de Mayo de 2011, y no hace falta estar registrado. La diferencia con la Wikipedia es que la conocida enciclopedia libre cuestiona y puede llegar a borrar ciertos artículos que no tengan un contenido totalmente académico, mientras que en la web que acaba de nacer estos textos no se van a restringir (aunque sí a moderar). Se busca, como en la original, un punto de vista neutro, y el formato es muy similar.

A la enciclopedia colaborativa se añade un Banco de Ideas, una web en la que se pueden subir materiales -como vídeos o fotos- de este tema, destinados a agrupar relatos individuales del movimiento y que servirán para ilustrar los artículos de la 15MPedia. Los impulsores de la iniciativa preparan un documental y un libro -que se presentarán en septiembre- con la narración de lo acontecido en Madrid desde mayo de 2011. Otras ciudades, como Málaga y Sevilla, han iniciado proyectos paralelos.

\section{f) La wikipedia española: Enciclopedia Libre Universal en Español}

A la sombra de Wikpedia y su versión en español, empiezan a surgir proyectos similares bajo la denominación de enciclopedias digitales libres en torno a un tema (educación ${ }^{19}$, idiomas ${ }^{20}$, jurisprudencia ${ }^{21}$, energía solar ${ }^{22}$, urbanismo ${ }^{23}$, etc.) o, incluso, a una región (Wikanda ${ }^{24}$, la enciclopedia de Andalucía, WikiSalamanca ${ }^{25}$, WikiRioja ${ }^{26}$, Toledo $^{27}$, Vilapedia ${ }^{28}$, de la localidad castellonense de Villareal, etc.)

\footnotetext{
${ }^{17}$ http://wiki.15m.cc/wiki/Portada [Consultado el 28.09.13]

${ }^{18}$ http://politica.elpais.com/politica/2012/06/07/actualidad/1339093701_423187.html [Consultado el 28.09.13]

${ }^{19} \mathrm{http} / / /$ es.wikieducator.org/P\%C3\%A1gina_Principal [Consultado el 28.09.13]

${ }^{20} \mathrm{http} / / / \mathrm{www}$.wikilengua.org/index.php/Portada [Consultado el 28.09.13]

${ }^{21}$ http://es.jurispedia.org/index.php/P\%C3\%A1gina_Principal [Consultado el 28.09.13]

${ }^{22}$ http://www.solarpedia.es/index.php/Portada [Consultado el 28.09.13]

${ }^{23} \mathrm{http}: / /$ www.urbipedia.org/index.php/P\%C3\%A1gina_de_Portada [Consultado el 28.09.13]

${ }^{24} \mathrm{http}: / /$ www.wikanda.es/wiki/Portada [Consultado el 28.09.13]

${ }^{25} \mathrm{http} / / / \mathrm{www}$.wikisalamanca.org/?title=Portada [Consultado el 28.09.13]
} 
Destacamos la Enciclopedia Libre Universal en Españo ${ }^{29}$, un proyecto para divulgar la cultura y el conocimiento y desarrollar a través de Internet una enciclopedia libre y gratuita en español en el que todos pueden colaborar elaborando nuevos artículos o ampliando los existentes, y participando en las muchas actividades que prepara. Con links interesantes, atractivos e interactivos, como Búsquedas, artículo destacado, ċo sabías?, citas de personajes biografiados, eventos, organizaciones culturales, etc., la wikipedia española crece a un ritmo lento pero progresivo: A finales de junio de 2012 cuenta con casi 48.000 artículos y más de 13.500 imágenes. Se puede ver y participar en algunos eventos que nos depara el año o involucrarte en las propuestas de las más importantes organizaciones del mundo de la cultura en español.

La Enciclopedia Libre Universal en Español, alojada en un servidor cortesía de la Universidad de Sevilla, es un proyecto para desarrollar a través de Internet una enciclopedia de calidad, abierta y gratuita en español, que se convierta en una obra de referencia obligada dentro del mundo hispano, tal y como la propuso Richard Stallman en Enciclopedia Universal y Recursos de Enseñanza Libres. El proyecto se sustenta en tres pilares: calidad, disponibilidad y neutralidad.

\section{CONCLUSIONES}

Después de cinco siglos de dependencia de la tecnología tipográfica, el final del siglo XX nos ofreció una revolución tecnológica -social y cultural- hasta entonces impensable (offset, fotomecánica, computadores, autoedición, impresión en color, televisión y radio) que encuentra su punto culminante en el desarrollo de Internet. $Y$ ya en el siglo XXI otra vuelta de tuerca, el desarrollo Web 2.0, ofrece un nuevo panorama en el que todos esos desarrollos tecnológicos se unen para proponernos un panorama en el que el individuo se vuelve protagonista principal de la comunicación y se coloca en la vanguardia en el mismo plano que las empresas de comunicación. Es decir, cualquier persona con un ordenador y un acceso a Internet se vuelve en un potencial comunicador casi profesional.

Uno de los problemas fundamentales al que se enfrentan tanto docentes como estudiantes de Ciencias de la Comunicación en su vida académica es el de poner en práctica los conocimientos que van adquiriendo. Las nuevas tecnologías de la información han facilitado mucho el proceso, sin embargo falta todavía una implicación por parte de todos los miembros de la comunidad educativa superior que facilite la inclusión de todas esas posibilidades en nuestra mano para realizar una inmersión efectiva en el desarrollo de nuevos medios de comunicación en Internet.

¿Qué conseguiremos con ello? Además de esa implicación por parte de todos los alumnos de comunicación en general, una salida al mundo real desde el mundo virtual

\footnotetext{
${ }^{26}$ http://wikirioja.com/index.php?title=Portada

${ }^{27}$ http://wiki.mitoledo.com/ [Consultado el 28.09.13]

${ }^{28} \mathrm{http}: / /$ www.vila-real.info/vilapedia/index.php?title=P\%C3\%A0gina_principal [Consultado el 28.09.13]

${ }^{29}$ http://enciclopedia.us.es/index.php/Enciclopedia_Libre_Universal_en_Espa\%C3\%B1ol [Consultado el 28.09.13]
} 
como supone cualquier medio que esté en Internet. Desgraciadamente en España no se le da la importancia que merece a los medios de comunicación universitarios. La producción literaria se limita a la importancia de los textos eminente científicos. Sin embargo un proyecto serio de medio de comunicación universitario ofrecerá necesariamente información y comunicación en un lugar donde apenas existe. La versión papel de la mayoría de medios en internet todavía es muy pobre en muchas ocasiones y el trabajo del docente y del técnico especializado es poner de relieve las virtudes de un proyecto que tiene sus pilares en ambas posibilidades, tanto online como la física o en papel.

El problema en estos casos viene de la mano de la financiación de tales proyectos. Al estar en una esfera un tanto ambigua (financiación, publicidad, rentabilidad, inversión) no llegan a cristalizarse en proyectos concretos y de larga duración. La actual crisis también nos empuja a las dificultades a la hora de encontrar inversión de capital para semejantes proyectos. La publicidad es un mercado de momento cautivo, y como motor de la comunicación tiene sus dificultades que no son objeto de este estudio pero que sí debemos tener en cuenta. El problema añadido es la medición de audiencias en Internet, y relacionado con lo comentado. Este tipo de ranking, de Webometrics, respaldados por instituciones de prestigio ayuda a avanzar en este sentido.

Por ello este estudio nos lleva a precisar que, de una parte haría falta incluir este nuevo parámetro en los estudios o ranking sobre webs universitarias, ya que no sólo afecta a los estudiantes o alumnado de comunicación sino que afecta a toda la comunidad universitaria en general. $Y$ de otra parte la necesidad de poner en marcha proyectos de forma general, no realizados por un departamento único o por una persona profesor en concreto, sino en los que se implique y se invierta recursos tanto económicos como personales para tratar de salir con éxito al mundo profesional.

\section{BIBLIOGRAFÍA}

ALBORNOZ, Luis (2007). Periodismo digital: los grandes diarios en la red. Michigan: La Crujía.

ALCONADA MON, Hugo (2009). Los secretos de la valija. Madrid: Planeta.

ALCONADA MON, Hugo (2011). Las coimas del gigante alemán. Madrid: Planeta.

ALLAN, Stuart (2006). Online News, Berkshire: McGraw Hill.

BAVIERA PUIG, Tomás (2009). "Las posibilidades informativas de los blogs", en FLORES, Jesús y ESTEVE, Francisco (edit) Periodismo Web 2.0. Madrid: Fragua.

BO, Leuf y CUNNINGHAM, Ward (2001). The Wiki Way: collaboration and sharing on the Internet. Michiga: Adison-Wesley. 
BRADSHAW, P. (2007). "Un modelo para la redacción del siglo XXI". Cuadernos de Periodistas, 12. Madrid, APM, pgs. 59-73.

BRIGGS, M. (2007). Journalism 2.0. Austin: Knight Center of Texas University.

CEBRIÁN HERREROS, M. (2008). "La web 2.0 como red social de comunicación e información". Estudios sobre el Mensaje Periodístico, 14; 345-361.

CHATFIELD, T. Brian (2009). The complete guide to wikis. Ocala: Atlantic Publishing Group.

FLORES, Jesús (2009): "Nuevos modelos de comunicación, perfiles y tendencias en las redes sociales". Revista Comunicar no 33, pgs. 73-81.

FUMERO, Antonio y ROCA, Genís (2007). Web 2.0. Madrid: Fundación Orange.

KLOABS, Joan E. (2006) Wikis: tools for information work and collaboration. Cambridge: Chandos.

MORAL, José Antonio del (2007). "Redes sociales y wikis" en ROJAS, Octavio; ANTÚNEZ, José Luis; GELADO, José Antonio; MORAL, José Antonio del; CASAS ALATRISTE, Roger (2007): Web 2.0 Manual [no oficial] de uso (pgs. 45-60) Madrid: ESIC.

NEGROPONTE, Nicholas P. (1995). Being Digital. New York: Vintage Books

NOGUERA, José Manuel (2012). Redes y Periodismo: cuando las noticias se socializan. Barcelona: UOC.

PÉREZ TORNERO, José Manuel y TEJEDOR CALVO, Santiago (2010). "Los wikidiarios y la comuniación online" en CEBRIÁN, Mariano (coord): Desarrollos del periodismo en Internet (pgs. 219-236). Zamora: Comunicación Social.

RICHARDSON, Will (2009). Blogs, wikis, podcasts and other powerful web tools for clasroom. Thousand Oaks: Corwin Press.

RUIZ SOROA, José María (2010). El esencialismo democrático. Madrid: Trotta.

SMITH, Anthony (1983). Goodbye Gutenberg. La revolución del periodismo electrónico. Barcelona: Gustavo Gili.

VARELA, J. (2005). "El asalto a los medios sociales". Cuadernos de Periodistas. Madrid: APM.

WEST, James A. y WEST Margaret L. (2009). Using wikis for online collaboration. San Francisco: Jossey Bass. 
WOODS, Dan y THOENY, Peter (2007). Wikis for dummies. Indianápolis: Wiley Publishing.

\section{Elvira Calvo}

Profesora de Información Audiovisual en la facultad de CC de la Información de la Universidad Complutense desde 1997 (Departamento de Periodismo II), participa activamente en proyectos de investigación y de innovación y mejora de la calidad docente. Profesora invitada por las Universidad de Zaragoza, Bamber (Alemania), Lusofona do Porto (Portugal) y la Bressanone-Brixen (Italia). Autora del libro "La información económica en televisión", cuenta con mas de cuarenta contribuciones entre comunicaciones a congresos, artículos en revistas científicas y capítulos de libros. Profesionalmente, cuenta con 25 años de experiencia en el periodismo activo, desarrollando labores de redacción, locución y producción en prensa, radio y televisión (El Diario Montañés, La Gaceta de los Negocios, Cadena SER, Telemadrid) y de comunicación empresarial e institucional en la Universidad Internacional Menéndez Pelayo, la CEOE, Eurocofín y en la entidad publica Red.es. 